Western Washington University Western CEDAR

Spring 2020

\title{
Spectral Variability of Weathered Basalts and Sandstones
}

\author{
Isabella Seppi \\ Western Washington University
}

Follow this and additional works at: https://cedar.wwu.edu/wwu_honors

Part of the Astrophysics and Astronomy Commons

\section{Recommended Citation}

Seppi, Isabella, "Spectral Variability of Weathered Basalts and Sandstones" (2020). WWU Honors Program Senior Projects. 399.

https://cedar.wwu.edu/wwu_honors/399

This Project is brought to you for free and open access by the WWU Graduate and Undergraduate Scholarship at Western CEDAR. It has been accepted for inclusion in WWU Honors Program Senior Projects by an authorized administrator of Western CEDAR. For more information, please contact westerncedar@wwu.edu. 


\section{Spectral Variability of Weathered Basalts and Sandstones}

In partial fulfillment of the requirements to graduate from the

Western Washington University

Honors Program

By

Isabella Seppi

October 2020

Advised By

Dr. Melissa Rice 


\begin{abstract}
Rock weathering on Mars is an important indicator of past environmental conditions. In order to understand the reflectance spectra taken from the rovers and orbiters on Mars, and how rock weathering rinds and coatings influence spectral observations, analog rocks can be studied in the lab (Minitti, 2007). The Martian surface is covered in basaltic sands, and clastic sedimentary rocks are present in many key locations. Previous laboratory studies have characterized weathering rinds on basalts, which are mineralogically analogous to the rocks on the Martian surface, but few studies have sought to characterize the weathering surfaces of sandstones, which are texturally analogous to many rocks on the Martian surface. In this study, we use a spectrogoniometer to measure visible/near-infrared (VNIR) reflectance spectra of naturally weathered surfaces of basalts and arkosic sandstones under different viewing geometries. We compare the photometric behavior of naturally weathered sandstones and basalts to investigate how those behaviors relate to textural similarities or differences of their weathered surfaces. We used scanning electron microscopy (SEM) to characterize the texture and mineralogy of their weathered surfaces and compared them to their rock interiors. Arkosic sandstone and basalt weathering rind have different absorption features and different near-infrared slope parameters due to their different mineral compositions; however, we focus on understanding the textural effects on the photometric behavior of different weathering rinds. Weathered sandstones are backscattering, which is consistent with the SEM images showing rough topography on the 10-100s of micrometer scale. Weathered basalts are forward scattering, which is consistent with the SEM images showing smooth topography on the $10-100$ s of micrometer scale. Furthermore, sandstones and basalts with texturally different weathering rinds show photometric differences. Basalts show an enhanced blue slope and sandstones do not. Photometric differences that have been noticed are in part related to the textural properties of the weathering rinds. This
\end{abstract}


investigation will enable us to better understand how spectra taken by the Mars rovers and orbiters are affected by the texture of the weathering rinds of sandstones and basalts, and how those can be linked to past environmental conditions and the geologic history of weathering on Mars. 
$\begin{array}{ll}\text { Abstract } & \text { ii }\end{array}$

List of Figures $\quad$ v

$\begin{array}{lc}\text { 1. Introduction } & 1\end{array}$

$\begin{array}{lr}\text { 2. Background and Significance } & 3\end{array}$

2.1 Geologic and Climate History of Mars 3

2.2 Evidence of Water on Mars

2.3 Rock Weathering 7

2.4 Spectroscopy and Photometry $\quad 8$

2.5 Next Steps in Mars Exploration $\quad 10$

2.6 Connections to Investigation 10

$\begin{array}{lr}\text { 3. Methods } & 12\end{array}$

3.1 Sample Collection $\quad 12$

3.2 Spectrogoniometer $\quad 12$

3.3 Scanning Electron Microscope 14

3.4 Interior Investigation 14

3.5 Data Analysis $\quad 15$

$\begin{array}{lr}\text { 4. Results } & 15\end{array}$

4.1 Spectral Data

4.2 SEM Data $\quad 17$

$\begin{array}{ll}\text { 5. Discussion } & 17\end{array}$

5.1 Mineralogy and Coatings 17

5.2 Photometric Trends 18

$\begin{array}{lr}\text { 6. Conclusions and Future Work } & 18\end{array}$

6.1 Summary of Findings $\quad 18$

6.2 Future Direction 19

7. Acknowledgements 19

$\begin{array}{lr}\text { 8. Bibliography } & 21\end{array}$ 


\section{List of Figures}

Figure 1. Image of a spectrogoniometer and its function 2

Figure 2. Geologic Timeline of Mars 4

Figure 3. Generalized Geologic Map of Mars 5

Figure 4. A delta at Eberswalde Crater 6

Figure 5. An image of a delta at Jezero crater showing clays and carbonates 7

Figure 6. An example of a basalt spectra 9

Figure 7. Images of a red basalt sample $\quad 13$

Figure 8. Images of an arkosic sandstone sample 13

Figure 9. Images of the interiors of a basalt and a sandstone sample 14

Figure 10. Spectra of the basalt and sandstone samples normalized to 2100nm 16

Figure 11. Spectra of the surfaces and interiors of the basalt and sandstone samples 16

Figure 12. Shadow images from the SEM showing the weathered and interior polished surfaces of the basalt and sandstone samples 


\section{Introduction}

Mars is the target of many space exploration programs that look for signs of life elsewhere in the solar system and universe. The mineralogy of rock surfaces found on Mars is studied to investigate the possibility of ancient Martian habitability. Rock weathering, the alteration of a rock's surface due to environmental exposure, is studied to investigate habitability by looking at exterior weathered rock surfaces, called weathering rinds (Dorn, 2013). It is important to study weathering, as it is indicative of the past environmental conditions that caused weathering. It can show important signs of precursors to life, such as water, or even biosignatures, due to biologic weathering. To better understand the data taken from Mars, Martian analog rocks are studied in the lab. A key tool to study Martian mineralogy and analog rocks is reflectance spectroscopy and photometry. Reflectance spectroscopy is a measure of the dispersion of light reflected from a surface into its component colors as a function of wavelength. Photometry, in planetary science, is the study of measurements of light with regard to how the human eye observes it (Shepard, 2020). It is studied by varying the angles at which light is emitted towards and detected off a surface. A tool to study photometry in the lab is a goniometer (Figure 1). This tool allows the incidence angle, the source of the light, and the emissions angle, where the light is detected, to be varied in order to investigate the scattering behaviors of surfaces. Backscattering is the reflection of light waves back in the direction they came and forward scattering is the reflection of light in the opposite direction to which they came (Figure 1). The photometric characteristics (backscattering and forward scattering characteristics) of a rock surface are affected by the topography on the surface. This topography is created by weathering processes and can therefore be indicative of weathering due to water, a precursor to life. 
In this study, the photometric behavior of naturally weathered arkosic sandstone (analogs to clastic sedimentary rocks found on Mars) was compared to that of basalts (analogs to basaltic sands and basalts on Mars) The basalts studied were Columbia River Flood Basalts (CRB) and the sandstones studied were Chuckanut Sandstone. Visible near-infrared (VNIR) reflectance spectra, defined as extending from $\sim 300$ to $5000 \mathrm{~nm}$, were used to study the sample surfaces and interiors. VNIR reflectance spectroscopy aided in investigating how photometric behaviors relate to textural similarities or differences of weathered surfaces. Sandstone weathering occurs when sand grains are plucked out of the sandstone surfaces, whereas basalt weathering occurs from chemical changes to the exterior of the rock, such as oxidation. It was hypothesized that this will cause the sandstone weathering surfaces to be rougher than the basalts and therefore more backscattering. Overall, this has the potential to help researchers understand the degree of weathering, indicative of past environmental conditions, of Martian rocks based on photometric changes observed in the spectra taken on Mars.

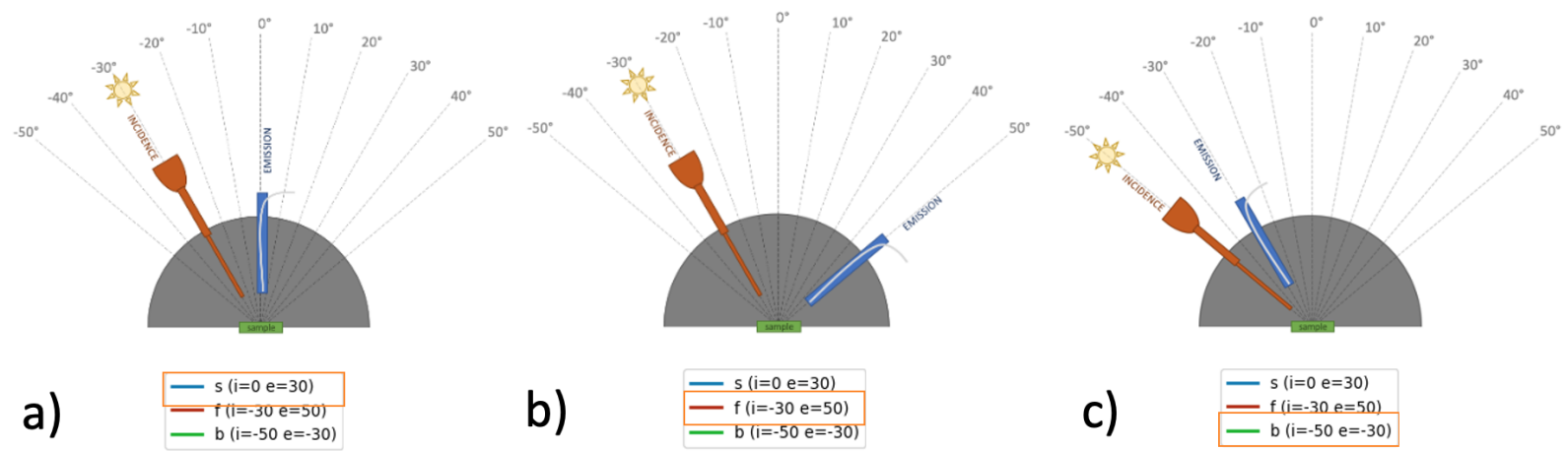

Figure 1. In the goniometer, the incidence angle is the source of the light and the emissions angle is where the light is detected. This image shows three possible geometries, (a) standard 
geometry, (b) forward scattering, and (c) backscattering; the geometries described in Hoza et al. 2019 (Image Credit: Olivia Finlay).

\section{Background and Significance}

\subsection{Geologic and Climate History of Mars}

Mars is the most Earth-like planet in the solar system, making it a great location for researchers to look for signs of life elsewhere. Mars researchers are interested in looking for evidence of water on Mars because water is a precursor to life (Cockell, 2020). This research on Mars can also help us learn about the history and future of life and geology on Earth. One important aspect of investigating ancient life on Mars is understanding the geologic and climate history of Mars. This can be better understood by studying how Martian rocks are altered by their environments. Their weathering surfaces can exhibit evidence of the weathering processes they experienced on Mars.

The current surface of Mars is inhospitable to life as we know it. In part, this is because surface liquid water is not present on Mars. If there is life on Mars it must be in the subsurface due to the lack of running surface liquid water. The surface is cold and dry and the atmosphere is 100 times less dense than that of the Earth, making liquid water unstable at the surface. As of present, all the surface water is currently located at the poles as ice caps. Wind is the most continually active weathering agent on Mars. Mars may have once been habitable if there was liquid water at the surface. This would have occurred when there was a warmer Martian surface temperature. A thicker atmosphere in the Martian atmosphere could have facilitated a warmer surface temperature, as it would have trapped heat around the planet. This would have allowed for liquid water to be stable on the surface of Mars (Baker, 2001). 
Earth is a little less than twice as large as Mars, meaning Mars was able to form and cool much more rapidly than Earth. The Martian interior cooled quickly on a geologic time scale causing plate tectonics, if ever present on Mars, to occur rapidly in the geologic history of the planet. This means Mars's magnetic dynamo, the rotating, convecting, and electrically conducting interior fluid of a planet maintaining a magnetic field, shut down quickly on astronomical time scales. This generated atmospheric loss. A lack of plate tectonics caused a lack of outgassing at plate boundaries, which would thicken the atmosphere. Furthermore, a magnetic field was not present to protect the atmosphere from being stripped away by charged particles from the sun. This led to the present conditions where the atmosphere is so thin that heat escapes the planet quickly and liquid water is unstable on the surface (Baker, 2001).

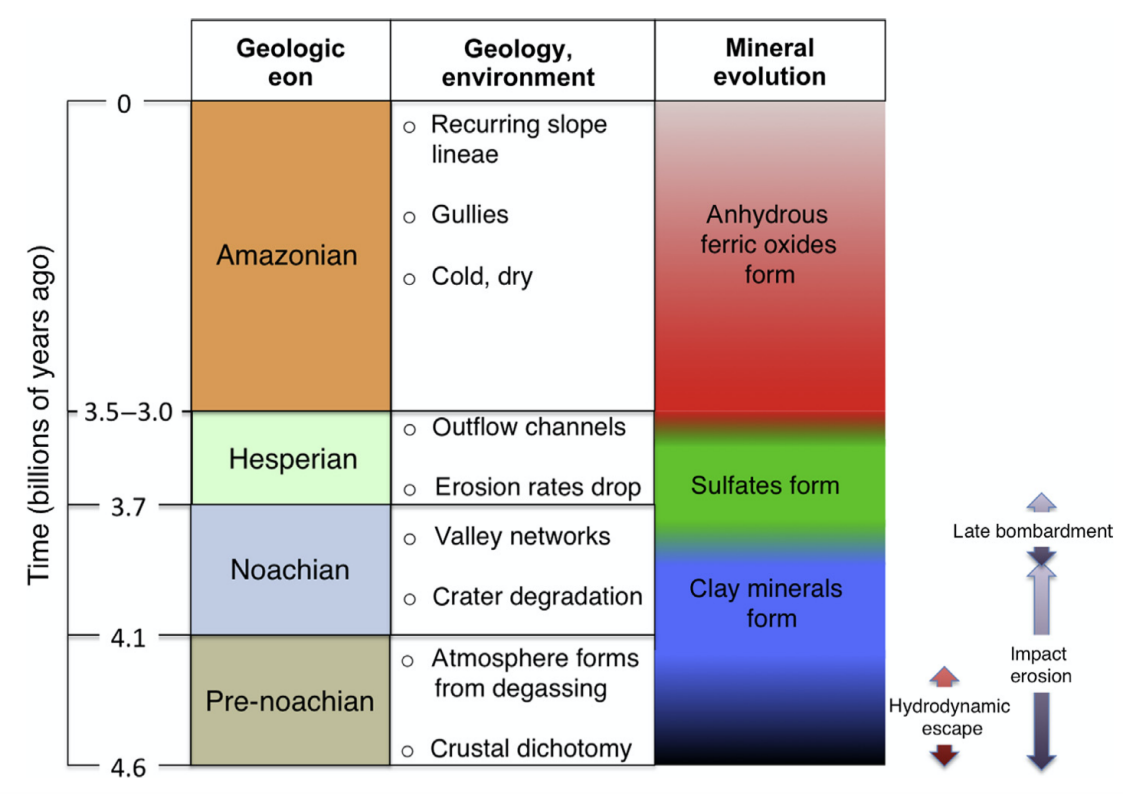

Figure 2. There are three main geologic periods on Mars, the Noachian, Hesperian, and Amazonian. (Catling, University of Washington, Dept. of Earth and Space

Sciences/Astrobiology Program) 


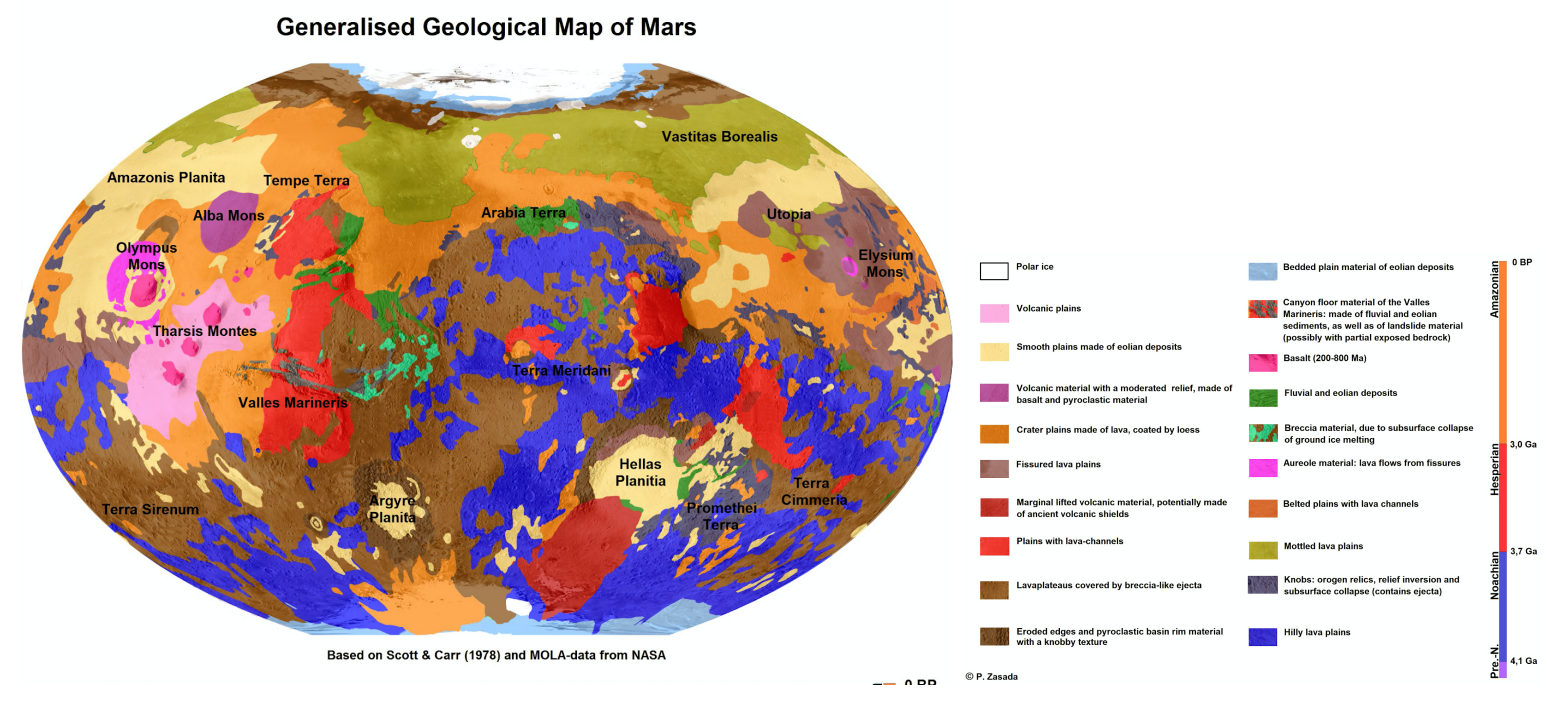

Figure 3. Rocks on Mars have been dated based off of craters. Rocks formed during the Noachian period can be found in the ancient heavily cratered uplands of Mars. They formed prior to 3.5 billion years ago. Rocks that formed during the Hesperian can be found in the intermediate cratered plains and those formed during the Amazonian are found in lightly cratered areas. (Zasada, 2013)

\subsection{Evidence of Water on Mars}

Part of the reason researchers are so interested in looking for signs of life on Mars is because there has been geologic evidence of water on Mars, a precursor to life (Cockell, 2020). Evidence of water on Mars includes fluvial landforms, landforms generated by running water, such as valley networks and deltas (Carr, 1996). Deltas form when water enters a large body of water, such as a lake (Figure 4). It is suspected that there were lakes in certain craters on Mars due to the presence of deltas. Mineral deposits found around certain deltas on Mars needed water to form. For example, carbonates found on the Martian surface are indicative of water. Spectral data taken at Jezero crater has shown that some sediments have minerals that indicate chemical alteration by water (Ehlmann, 2008). These sediments contain clays and carbonates (Figure 5). 
When looking at carbonate deposition there are biogenically formed carbonates and abiogenically formed carbonates. Biogenically formed carbonates would indicate past life on Mars. In 2010, the Spirit rover found outcrops rich in magnesium-iron carbonate in the Columbia Hills of Gusev crater. They most likely precipitated during the Noachian era, an era associated with volcanic activity, from carbonate-bearing solutions under hydrothermal conditions. Carbonates were also found on the rim of Huygens Crater, where rim exposed material was dug up from the impact that created Huygens. These showed evidence of a thicker carbon dioxide atmosphere with abundant moisture and these kinds of carbonates only form when there is a lot of water (Baker, 2001).

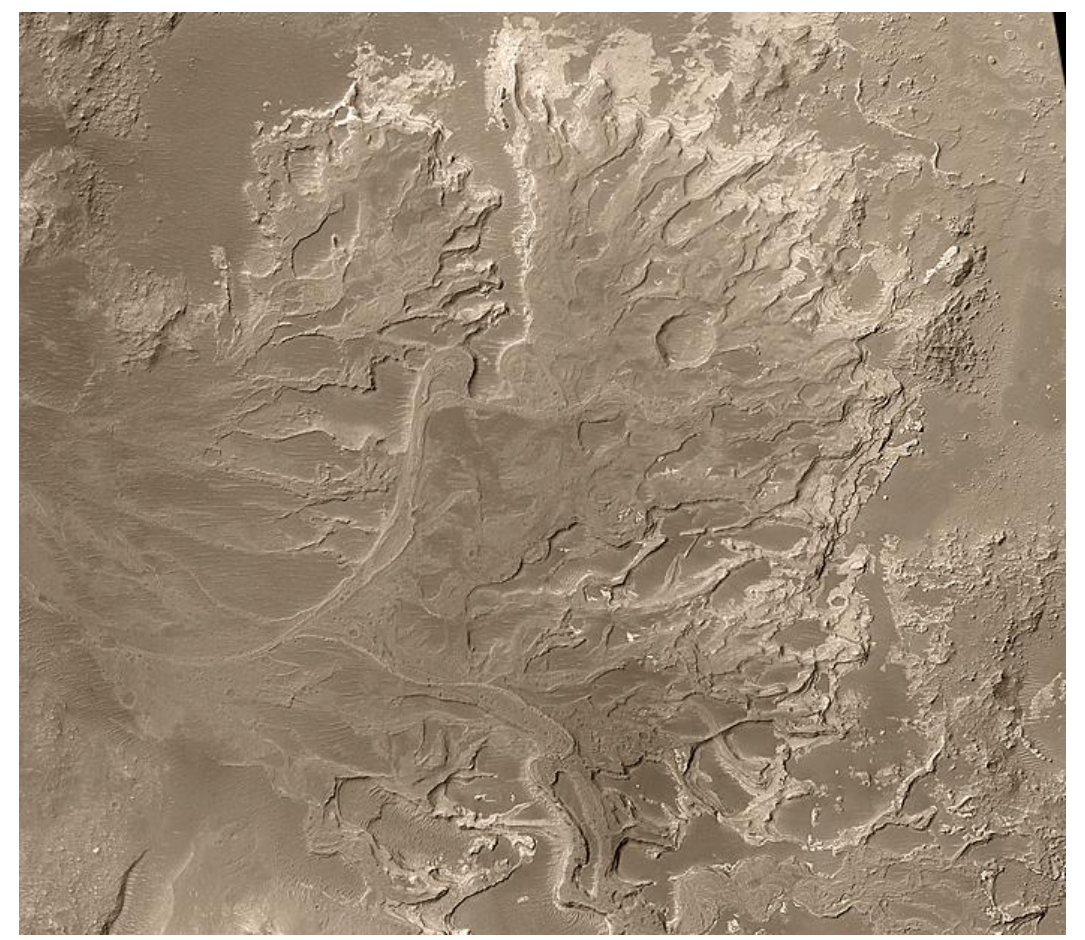

Figure 4. A delta at Eberswalde Crater. (NASA/JPL/Malin Space Science Systems) 


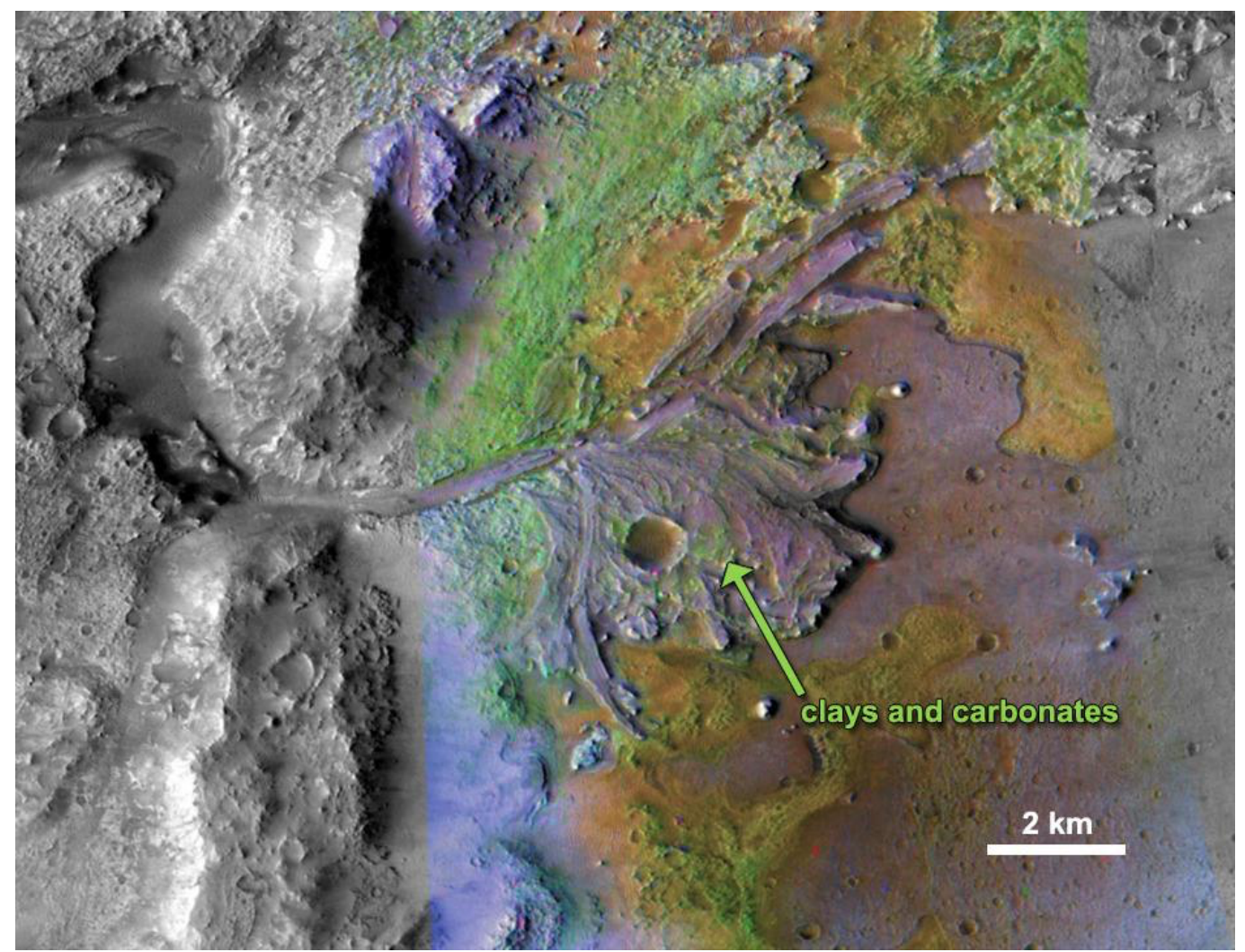

Figure 5. A delta at Jezero crater, which was chosen as the landing site for the Mars 2020 rover mission. This image combines information from two instruments on NASA's Mars Reconnaissance Orbiter, the Compact Reconnaissance Imaging Spectrometer for Mars and the Context Camera. An arrow indicates where clays and carbonates are found. (NASA/JPL)

\subsection{Rock Weathering}

Rock weathering surfaces on Mars are indicative of past environmental conditions that caused the weathering. Rock weathering is the alteration of a rock surface due to environmental exposure. Weathering leads to differences in both mineralogy and surface texture. Physical weathering causes changes to the texture whereas chemical weathering causes changes in the mineralogy and in part the texture. Weathering rinds refer to chemically altered outer layers of a rock due to weathering (Dorn, 2013). The weathering processes, caused by water that researchers 
are interested in, on Mars are most likely from the Amazonian era (Carr, 1996). Rock weathering surfaces on Earth can be analogous to rock weathering on Mars and can be studied to better understand weathering on Mars.

\subsection{Spectroscopy and Photometry}

Evidence of water can be detected on Mars through the use of spectroscopy and photometry to look at weathering surfaces (Figure 5). Spectroscopy pertains to the dispersion of an object's light into its component colors and is a measurement of a quantity as a function of wavelength or frequency and photometry "is defined as the science of the measurement of light in terms of how the human eye perceives it." (Shepard, 2020). In this case, when light hits a weathered rock surface light is either absorbed or reflected by the surface and the reflected light is plotted in the form of a graph indicating the reflectance at different wavelengths. In the lab, VNIR reflectance spectroscopy, extending from $\sim 300$ to $5000 \mathrm{~nm}$, was studied.

Spectroscopy is studied by bouncing light off surfaces. When the light interacts with a surface, compounds on it are excited by the electromagnetic radiation provided by the light source. Their molecules absorb energy from the electromagnetic radiation, become excited, and jump from a low-energy ground state to a higher energy state of excitation. Energy is then released in the form of a reflected light wave. When studying reflectance spectroscopy, reflected wavelengths are detected and plotted. Absorption features are created in the spectra where energy, at certain wavelengths, has been absorbed (Figure 6). Molecules within a sample only absorb wavelengths with energies corresponding to the energy difference of their energy level transition (Bishop, 2019).

A spectrogoniometer is a tool to study spectrometry at various angles. A goniometer is an 
instrument for the precise measurement of angles. The angle of emission is where light is detected and the incident angle is where light is emitted onto the surface (Figure 1).

It is possible to tell what minerals are present in a sample from their absorption features. This is because certain minerals contain certain compounds and molecules. Furthermore, some minerals are stronger in backscattering geometry and some in forward scattering geometries, so it's possible to tell what minerals make up a sample by using different geometries. The forward and backscattering properties of materials depend on mineralogy and texture (Bishop, 2019).

The instrument relevant to this research on the Curiosity Rover is the Mascam instrument, and on the Perseverance Rover is the Mascam- $Z$ instrument. Mascam- $Z$ is equivalent to Mascam but with zoom capabilities (Williford et al., 2017). VNIR data taken from the Curiosity Rover has shown evidence for clay minerals. These minerals were found at limited locations and suggest ancient alteration of hydrothermal and sedimentary origin. Chemical and mineralogical alterations to rock surfaces due to weathering on Mars look different in the spectra taken by the rovers than unaltered basalt surfaces. This is because VNIR spectra of weathered rock surfaces are typically more red and bright than surfaces that have not been wethered to the same degree (Kraft et al., 2003).

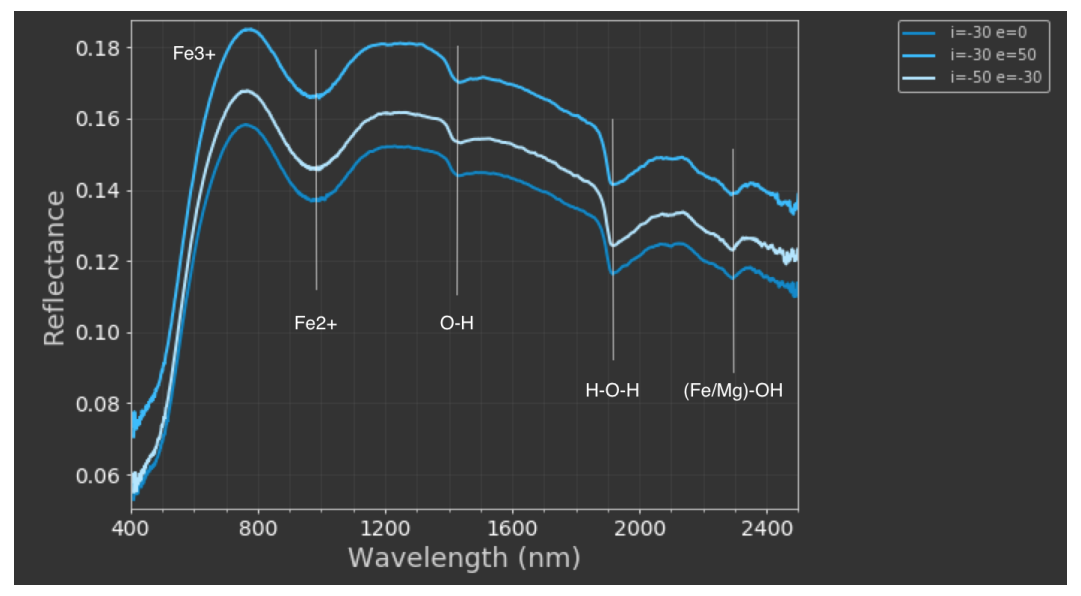


Figure 6. An example of a basalt spectra. Major absorption features are labeled. The steep slope in the short wavelengths is due to iron oxidation and the $\mathrm{O}-\mathrm{H}$ absorption feature is due to clays.

\subsection{Next Steps in Mars Exploration}

The field of Mars exploration has so far been restricted to analysis of Earth-based analogs, models, and remote observations. The Mars 2020 Rover, Perseverance, will, however, be preparing for rock and soil sample returns from Mars. The Perseverance rover will also be looking for signs of ancient life. During this mission, biosignatures, indicative of ancient life, may be found, or a lack of signatures could put constraints on where life could be found on Mars. The rover will be landing at Jezero Crater where orbiters have identified clays and carbonates that are indicative of chemical alteration by water (Farley et al., 2020).

\subsection{Connections to Investigation}

Basaltic sands cover the Martian surface, and clastic sedimentary rocks can be found in many principle locations. The goal of my summer research was to compare the reflectance of the weathering surfaces of basalts (volcanic igneous rocks) and arkose sandstones (sedimentary rocks). It was important to study sedimentary rocks to investigate how sedimentary production affects spectra. Previously, the Western Washington University Mars Lab researched spectra taken from basalt weathering rinds. Sandstones, texturally analogous to rocks on Mars, had yet to be studied. The Perseverance Rover was going to a fluvial deltaic area, Jezero Crater, and therefore would potentially study sandstone lithologies, making this research relevant to current missions. Furthermore, there had not been extensive research of spectra taken off weathering surfaces at multiple angles. Rovers and orbiters are not always taking spectra with the same incident and emission angles so it was important to see how changing geometries affect the 
spectra taken from the weathering surface (Campbell, 2007).

For this investigation, sandstones were collected from the Chuckanut formation of Western Washington. There is no perfect analog to the rocks on Mars, however, these sandstones were good to investigate as they were texturally interesting. While not compositionally similar to the rocks on Mars, they contained feldspar similar to basalts on Mars. Columbia River Flood Basalt samples that were held in the Mars Labs sample collection were also investigated, and were analogous to flood basalts on Mars.

It was hypothesized that visible and near-infrared spectral differences in slope and absorption features would be indicative of mineralogical differences and that photometric similarities or differences would be affected by viewing geometries. Photometric similarities were thought to be, in part, related to the different textural properties of the weathering rinds. Some minerals have stronger reflectance in the backscattering or the forward scattering geometries, causing photometric changes to not be solely related to textural properties. It was suspected that the sandstones and basalts would have spectral differences at both forward scattering and backscattering geometries but would potentially have important photometric similarities if they had texturally similar weathering rinds. The main hypothesis was that the sandstone surfaces would be rougher than the basalt surfaces and therefore would be more backscattering. The sandstone surface was hypothesized to be rougher than that of the basalt due to the differences in how their rock surfaces weather. When sandstone weathers sand grains are plucked out of weathering surfaces, making them rough, and when basalt weathers coatings and rinds form on the weathering surfaces, smoothing them out.

This work was in preparation for a NASA research grant led by Profs. Melissa Rice, Mike Kraft 
and Sean Mulcahy to use a hemispheric goniometer to investigate spectra off Mars analog rocks (Rice et al., 2019). It followed the work of Kathleen Hoza to create a goniometer to look at naturally weathered and synthetically coated basalts. Her work found that weathering affected scattering lobs and that there were changes from forward to backscattering on surfaces depending on weathering surface. This investigation built off this work by comparing the effects of weathering on basalts to that of sandstones (Hoza, 2019). This work also follows Kristiana Lapo's work to study coated basalt sands and how coatings on sands affect spectra. This investigation was done in conjunction with a student Alivia Eng, studying the spectral effects of different silica coating thicknesses on basalts. When looking at the spectra taken by the rovers, this research could be used to aid in differentiating between basaltic sands and basalt rocks. This could also be helpful in identifying rock coatings on Mars, as described in Minitti et al. (2007)

\section{Methods}

\subsection{Sample Collection}

The first step of this project was to collect samples and to identify Columbia River Basalt (CRB) samples from Eastern WA (Michalski et al., 2006), that were currently in the Mars Lab collection. Chuckanut Sandstone was collected from the Chuckanut Formation (Mustoe et al., 2007) and was selected looking for diverse weathering surfaces. Samples with darkened and/or reddened weathering surfaces were most interesting for this investigation. Locations with honeycomb weathering and State Parks and protected lands were avoided.

\subsection{Spectogoniometer}


In this study, a spectrogoniometer was used to measure visible/near-infrared (VNIR) reflectance spectra of the rock surfaces and interiors under different viewing geometries. Spectra were collected by the goniometer from eight CRB samples and eight Chuckanut Sandstone samples. Three different geometries were used: backscattering, forward scattering and a standard geometry (Figure 1). After looking at the spectra, two basalt rocks and two sandstone rocks, that had interesting spectra, were identified to further investigate the similarities and differences in the textures of their weathering rinds.
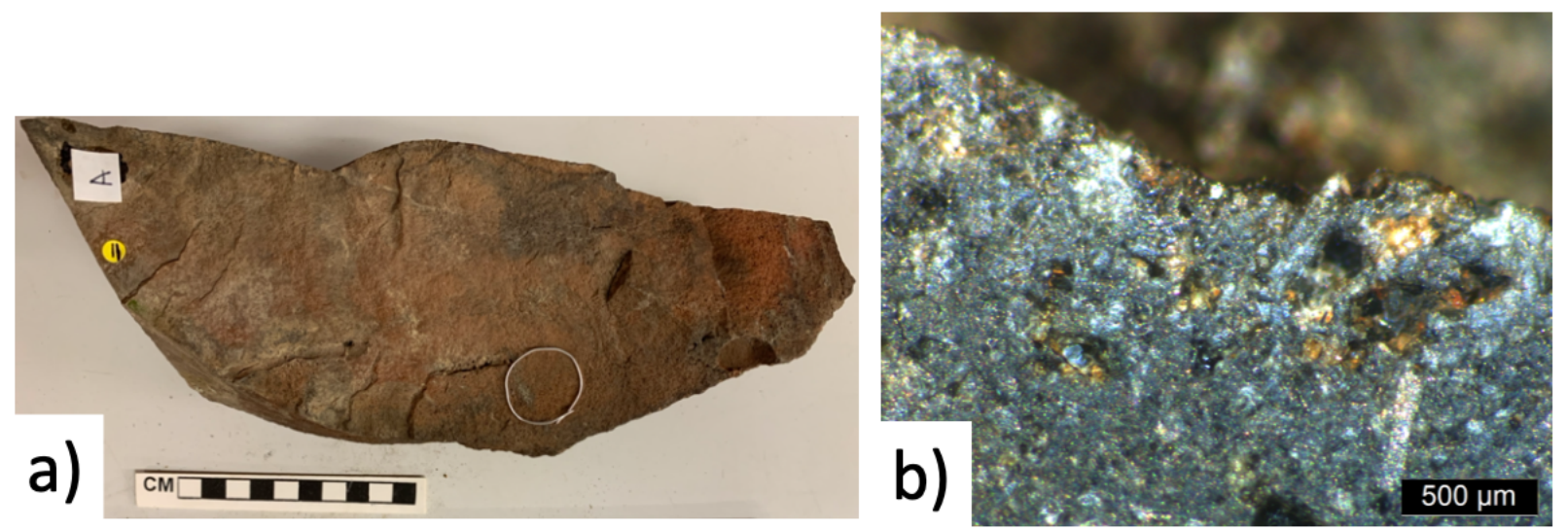

Figure 7. (a) Red basalt sample with ring indicating where spectra were taken. (b) Cross sections showing a basalt weathering rind polished to a 2400- grit size.
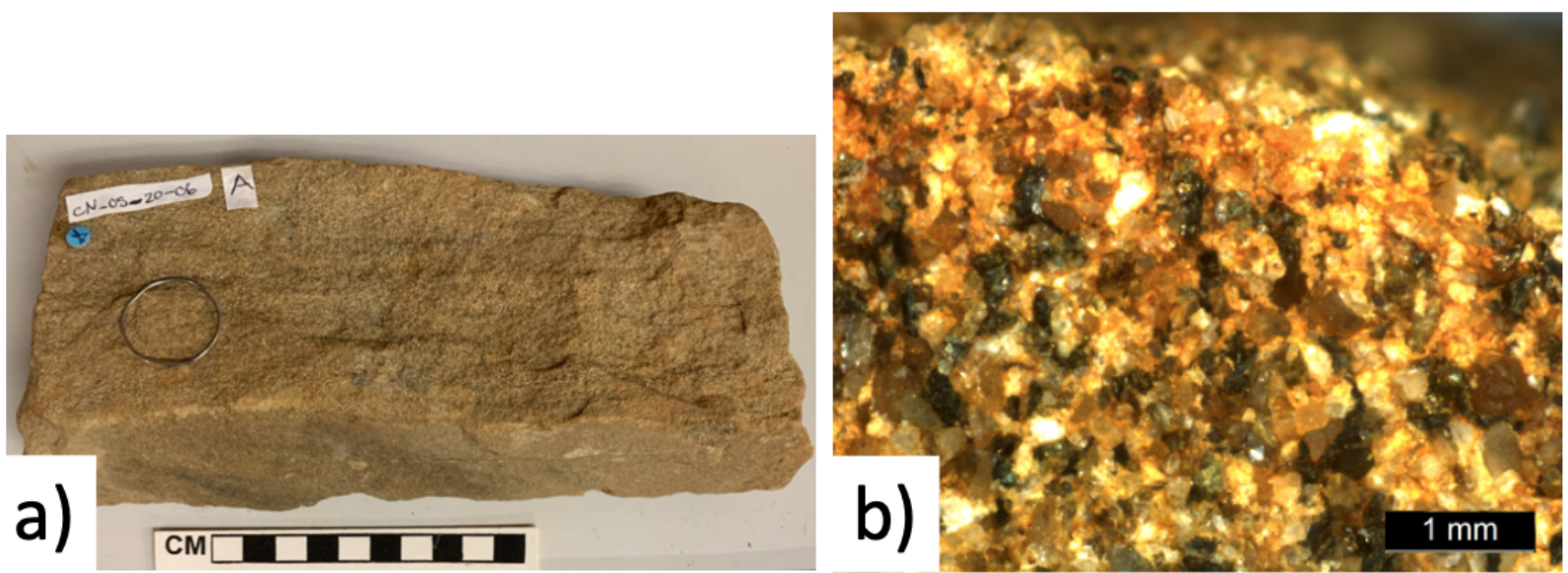
Figure 8. (a) Arkosic sandstone sample with ring indicating where spectra were taken. (b) Cross sections showing a sandstone polished to a 600 -grit size.

\subsection{Scanning Electron Microscope}

These rocks were then cut to fit into the scanning electron microscope (SEM). The SEM uses electrons in a beam to interact with the sample surface, producing signals that obtain information about the surface topography and composition of a sample. The weathering surfaces were investigated under the SEM with the primary goal of characterizing the textures of the weathered surfaces. It was also done to measure rock coatings, to look at micro-fissures, and to look at mineralogical and petrologic properties of the rocks.
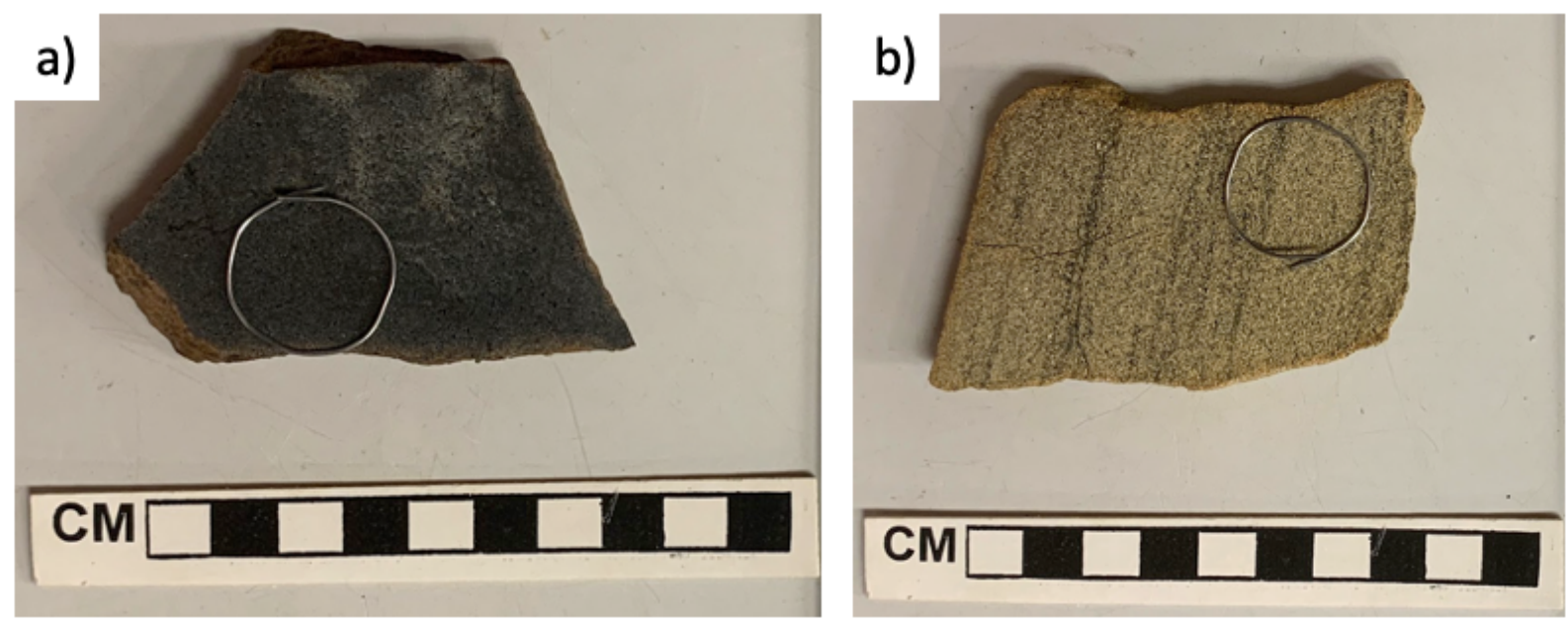

Figure 9. (a) Interior of red basalt sample with ring indicating where spectra were taken. (b) Interior of arkosic sandstone sample with ring indicating where spectra were taken.

\subsection{Interior Investigation}

These rocks were then cut open and their internal surfaces were polished. To preserve the 
weathering rind the sandstone samples were embedded in epoxy before polishing. The samples used to look at under the SEM were polished to a 2400 grit-size. Samples used for spectroscopy were polished to a 600 grit-size. The polished interiors were investigated under the SEM and electron dispersive spectroscopy (EDS), a feature of the SEM, was used to characterize the mineralogy of the samples. Spectra were also taken along the interior polished surfaces as well.

\subsection{Data Analysis}

To analyze the data, differences in spectra of the basalts versus sandstones taken along their weathering rinds and internally were investigated and compared to their textural and compositional differences found using the SEM. The photometric effects of changing geometries were compared to the surface roughness found using the SEM along these different surfaces to see how sandstone and basalt textures affect the spectrum.

\section{Results}

\subsection{Spectral Data}

Arkosic sandstone and basalt weathering rind have different absorption features and slope parameters due to mineralogical differences. A $680 \mathrm{~nm}$ absorption on the sandstones has been found to be chlorophyll. The sandstone was found to be more reflective than basalt.

Changing geometries had the least effect on the spectra of the weathered sandstone surface. The slopes, local maximum and local minimum values at different geometries are closer together in spectra, taken from weathered sandstone surface, than from the weathered basalt surface. Sandstone had its highest reflectance in the backscattering geometry and basalt had its highest reflectance in the forward scattering geometry. 

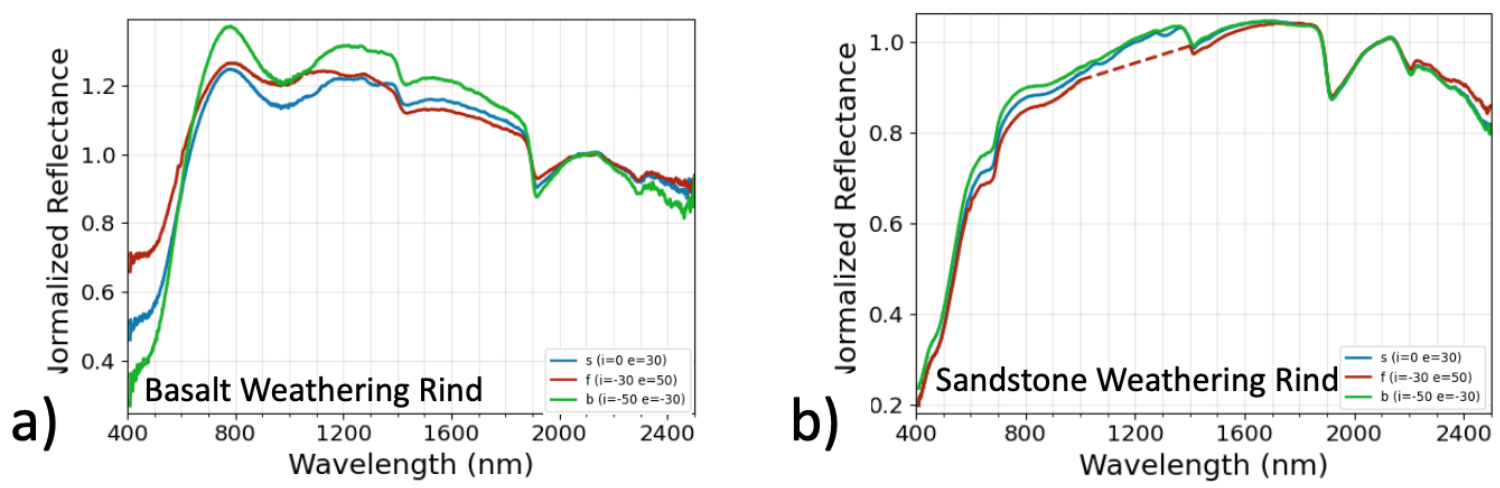

Figure 10. Changes in slopes at different geometries is more noticeable in the (a) basalt spectra as compared to the (b) sandstone. The sandstone spectra's slopes and band depths are mostly unchanged for different geometries. The spectra is normalized to $2100 \mathrm{~nm}$. The basalt spectra shows an enhanced blue slope.

a)

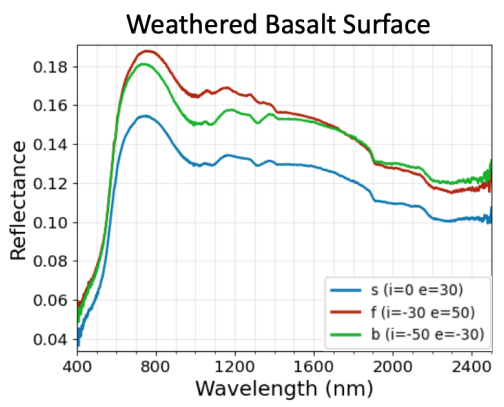

c)

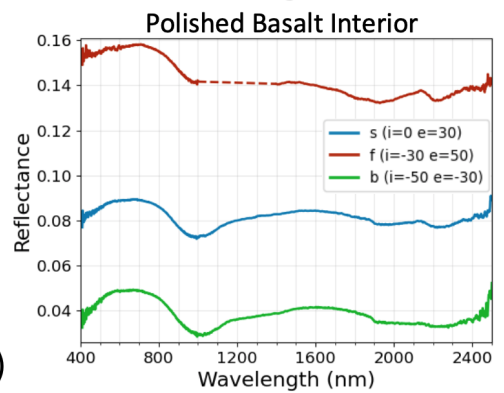

b)

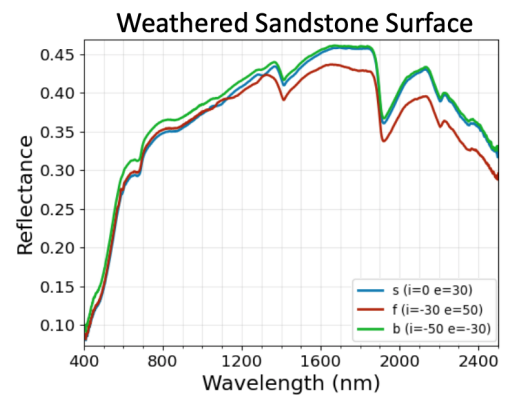

d)

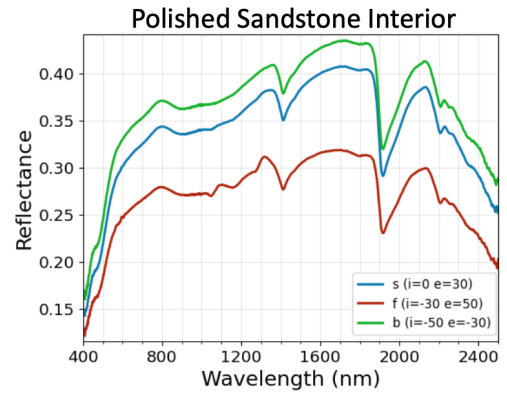

Figure 11. The dotted line in the (c) spectra of the polished basalt interior is where polarization artifacts from the spectogioniometer have been removed. Polarization artifacts can also be seen at these wavelengths in the forward scattering geometry for the (a) weathered basalt surface and the (d) polished sandstone interior. 


\subsection{SEM Data}

Looking at the SEM images, on the millimeter scale the weathered basalt surface was smoother than the weathered sandstone surface. The polished sandstone interior was the roughest surface and the polished basalt interior was the smoothest surface.
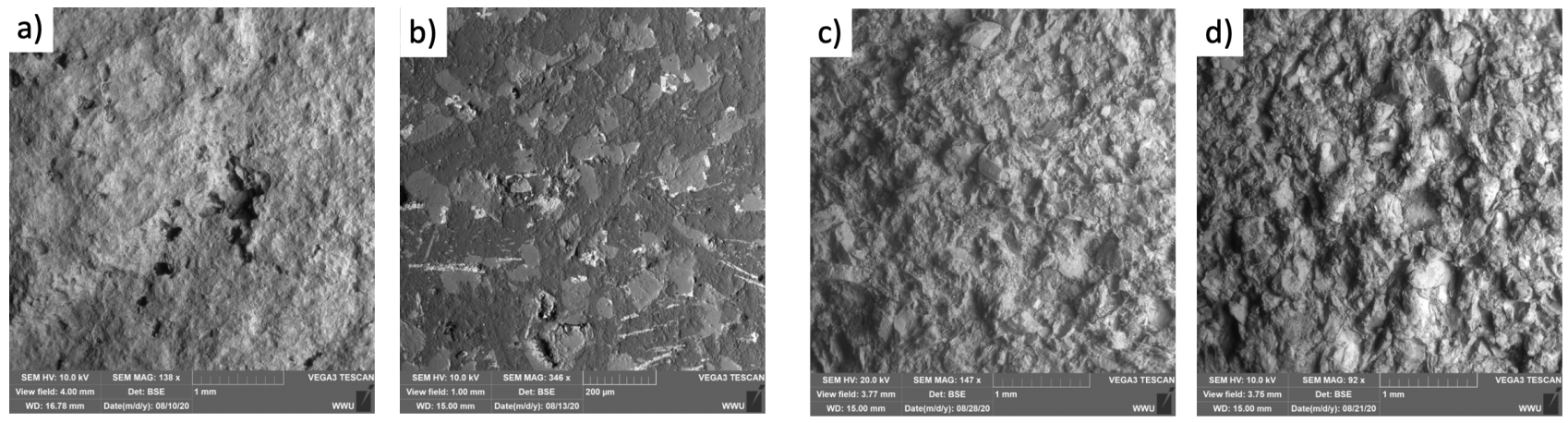

Figure 12. Shadow images of the (a) weathered basalt surface, (b) basalt interior polished to 2400-grit, and of the (c) weathered sandstone surface, and (d) sandstone interior polished to 2400-grit..

\section{Discussion}

\subsection{Mineralogy and Coatings}

The sandstone is more reflective than the basalt, due to mineralogy which affects the color of the sample. Dark samples are less reflective and therefore it is consistent that dark basalt surfaces are less reflective than light sandstone surfaces. The basalt sample has an enhanced blue slope consistent with a two-layer basalt coating model seen in Johnson et al. 2001 and Fischer et al. 1993. These changes present in the basalt literature are not seen in the sandstone sample. Looking at figure $11 \mathrm{~b}$ and $11 \mathrm{~d}$ you can see that the hydration bands, which are absorption features at $1400 \mathrm{~nm}$ and $1900 \mathrm{~nm}$, are larger for the polished sandstone interior. This is unusual 
and may be due to adsorption, the presence of hydrated minerals, or that the interior sample was not completely dry before spectra was taken off it.

\subsection{Photometric Trends}

There was a decrease in backscattering reflectance of polished basalt interior compared to weathered basalt surfaces because polishing creates mirror-like properties. This is consistent with polished basalt surface being significantly smoother on a smaller scale than the weathered surface. There is a decrease in forward scattering reflectance of the polished sandstone interior compared to the weathered sandstone surface due to the shadowing effect. The shadowing effect is where high topography blocks light from reaching certain regions on the surface of a rock. This is consistent with polished sandstone surface being rougher than the weathered sandstone surface. The polished surface was rougher because polishing caused grains to be plucked out of the sandstone surface. This occurred because the grains were not well cemented in the interior. There were also not biological and geological materials adhering to the surface and smoothing it out, like on the weathering rind causing the surface to be rougher. The hypothesis of this investigation was supported, and the rougher surfaces of the weathered sandstone surfaces did prove to be more backscattering than the smooth weathering surfaces found on the basalts.

\section{Conclusions and Further Work}

\subsection{Summary of Findings}

The smooth surfaces of the weathered basalt exteriors on the millimeter scale have a higher reflectance in the forward scattering geometry. The rough surfaces of the weathered sandstone exteriors on the millimeter scale have a higher reflectance in the backscattering geometry. The 
photometric effects seen in the spectra of weathered basalt exteriors are greater than those seen in the spectra of weathered sandstone exteriors. The initial hypothesis was supported and the rougher sandstone weathering surfaces were found to be more backscattering than the smoother basalt weathering surfaces.

\subsection{Future Direction}

The next step for investigating the weathering rinds of sandstones and basalts would include using X-ray diffraction (XRD) to characterize the mineralogy of the basalts and sandstones on both the internal uncoated surfaces and on the weathering rinds. The XRD is an instrument for analyzing the structure of a material from the scattering pattern produced when a beam of radiation or particles interacts with it (Hoza, 2019). The XRD will assist with interpreting how absorption features and different near-infrared slope parameters are affected by mineralogy.

In the future, it will also be important to characterize more weathering surfaces using the SEM and to study other sandstone lithologies, such as basaltic sandstone. This will further help in understanding how the textures of diverse weathering surfaces affect photometric behavior. Photometric behavior then has the potential to help researchers understand the degree of weathering on a rock surface. Studying the degree of weathering can aid in learning more about the environment in which a rock was shaped. This lab work can help researchers interpret data taken by the rovers on Mars and can ultimately be used to better understand the geologic history of Mars and its potential for habitability.

\section{Acknowledgements}

This project would not have been possible without the support and expertise of Ben Paulson, Dr. Michael Kraft, Kristiana Lapo, Dr. Sean Mulcahy, and Kathleen Hoza of the Western 
Washington University Geology Department. Special thank you to Dr. Melissa Rice for advising this project. This research was funded by the Washington NASA Space Grant Consortium Summer 2020 Research Internship and the NASA Solar Systems Workings Programs. It was presented to and supported by the Western Washington University Honors Program. 


\section{Bibliography}

Baker, V. (2001). Water and the martian landscape. Nature, 412, 228-236.

Bishop, Janice L., et al. (2019). Remote Compositional Analysis: Techniques for Understanding Spectroscopy, Mineralogy, and Geochemistry of Planetary Surfaces. Cambridge University Press.

Campbell, J.B. (2007). Introduction to Remote Sensing. Guilford Press, 101-121.

Carr, M. H. (1996). Water on Mars. New York: Oxford University Press, 3-29.

Cockell, C. S. (2020). Astrobiology: Understanding Life in the Universe. Wiley-Blackwell.

Dorn, R.I. (2013). 4.5 Rock Coatings. Treatise on Geomorphology, 4, 70-97.

https://doi.org/10.1016/B978-0-12-374739-6.00066-X

Ehlmann, B.L., Mustard, J.F., Murchie, S.L., Poulet, F., Bishop, J.L., Brown, A.J., Calvin, W.M., Clark, R.N., Des Marais, D.J., Milliken, R.E., Roach, L.H., (2008). Orbital identification of carbonate-bearing rocks on Mars. Science. 322, 1828-1832.

Farley, K.A., Williford, K.H., Stack, K.M. et al. (2020). Mars 2020 Mission Overview. Space Sci Rev 216, 142. https://doi.org/10.1007/s11214-020-00762-y

Fischer, E.M., \& Pieters C.M. (1993). The Continuum Slope of Mars: Bidirectional Reflectance Investigations and Applications to Olympus Mons. ICARUS, 102(2), 185-202. https://doi.org/10.1006/icar.1993.1043

Hoza, K.M. (2019). Photometric investigations of weathering rinds and coatings with implications for Mars (Master's dissertation). Available from WWU Graduate School Collection. 921.

Johnson, J.R., \& Grundy, W.M. (2001). Visble/Near-Infrared Spectra and Two-Layer Modeling of Palagonite-Coated Basalts. GEOPHYSICAL RESEARCH LETTERS, 28(10), 2101-2104. https://doi.org/10.1029/2000GL012669

Kraft, M.D., J.R. Michalski, T.G. Sharp (2003). Effects of pure silica coatings on thermal emission spectra of basaltic rocks: Considerations for Martian surface mineralogy. Geophys. Res. Lett., 30(24), 2288-4. doi:10.1029/2003GL018848.

Michalski, J. R., Kraft, M. D., Sharp, T. G., \& Christensen, P. R. (2006). Effects of chemical 
weathering on infrared spectra of Columbia River Basalt and spectral interpretations of martian alteration. Earth and Planetary Science Letters, 248(3-4), 822-829. DOI:

10.1016/j.eps1.2006.06.034

Minitti, M. E., C. M. Weitz, M. D. Lane, and J. L. Bishop (2007). Morphology, chemistry, and spectral properties of Hawaiian rock coatings and implications for Mars, J. Geophys. Res., 112, E05015, doi:10.1029/2006JE002839.

Mustoe, G. E., Dillhoff, R. M., and Dillhoff, T. A. (2007). Geology and paleontology of the early Tertiary Chuckanut Formation. Floods, Faults, and Fire: Geological Field Trips in Washington State and Southwest British Columbia. Geological Society of America Field Guide, 9, 121-135. doi:10.1130/2007.fld009(06)

Rice, M.S., Kraft, M., Mulcahy, S. (2019). Interpreting Rock Weathering on Mars Using Spectrogoniometry of Natural Rinds and Coatings: A Proposal to the NASA Solar System Workings Program Solicitation: ROSES-2018, NNH18ZDA001N-SSW.

Shepard, M. K. (2020). Introduction to Planetary Photometry. Cambridge University Press.

Williford, K.H, K.A. Farley, K.M. Stack, A.C. Allwood, D. Beaty, L. Beegle, R. Bhartia, A.J. Brown, M. de la Torre Juarez, S.-E Hamran, M.H. Hecht, J. Hurowitz, J.A. Rodriguez-Manfredi, S. Maurice, S. Milkovich, R.C. Wiens, (2017). The NASA Mars 2020 rover mission and the search for extraterrestrial life. From Habitability to Life on Mars, Chapter 11, Elsevier. 